\title{
DETERMINACIÓN DE OFERTA DE SUELO URBANO DISPONIBLE PARA RENOVACIÓN DENSIFICADA Propuesta metodológica
}

\author{
Determination of available urban land supply for densified renovation \\ Methodological proposal
}

\author{
Moreno Alba, Daniel \\ Dirección de Extensión y Servicios Externos, Pontificia Universidad Católica de Chile. dlmoreno@uc.cl \\ Figueroa Monsalve, Óscar \\ Dirección de Extensión y Servicios Externos, Pontificia Universidad Católica de Chile. ofiguero@uc.cl
}

\begin{abstract}
RESUMEN
La densificación y renovación en el desarrollo urbano, aparecen como la oportunidad para aprovechar las infraestructuras existentes al igual que dar más cabida de población sin necesidad de establecer límites urbanos cada vez mayores. No obstante, la determinación de aquellos predios o espacios en los que se podría densificar, varía de acuerdo a diversos factores, como por ejemplo el contexto normativo o el costo que significa la demolición de construcciones previas. La identificación de estos factores, al igual que el análisis territorial que conllevan, permite conocer qué zonas o terrenos son aptos para la densificación y renovación urbana. Por lo tanto, el propósito principal de esta propuesta, es dar a conocer una metodología para la determinación de suelo urbano disponible. Los objetivos complementarios abordan inicialmente los procesos de crecimiento urbano, tanto por extensión como por densificación, así como su justificación y propuestas de criterios básicos para una densificación integral.
\end{abstract}

Palabras clave: suelo urbano, densificación, renovación.

Bloque temático: análisis y proyecto territorial.

\section{ABSTRACT}

The densification and renewal of urban development appear as the opportunity to take advantage of existing infrastructures as well as to give more population capacity without the need to establish ever greater urban limits. However, the determination of those properties or spaces in which it could be densified varies according to different factors, such as, for example, the regulatory context or the cost of demolishing previous constructions. The identification of these factors, as well as the territorial analysis they entail, makes it possible to know which areas or lands are suitable for densification and urban renewal. Therefore, the main purpose of this proposal is to present a methodology for the determination of available urban land. The complementary objectives initially address urban growth processes, both by extension and by densification, as well as their justification and proposals for basic criteria for an integral densification.

Keywords: urban land, densification, renovation

Topic: territorial analysis and project 


\section{Introducción}

El crecimiento de las ciudades latinoamericanas ha tenido históricamente un fuerte componente de expansión que presiona un bajo uso del suelo y una caída de las densidades poblacionales promedio. Aunque últimamente se han verificado procesos de recuperación de áreas centrales, esto no ha sido aún suficiente como para revertir la tendencia a la des-densificación que ha imperado en las últimas décadas. Incluso cuando hay recuperaciones en las áreas más centrales de las ciudades, ello no ha impedido que se produzcan abandonos de otros sectores, en particular, en los llamados inner cities o pericentros.

En las áreas pericentrales deprimidas y que no han mostrado vocación esencial de centralidad, la obsoletización de lo construido1 (residencias, talleres, bodegas, etc.) difícilmente puede recuperarse y renovarse por falta de recursos y de atractividad de dichas zonas.

Sin embargo, hay méritos importantes en los procesos de renovación y densificación, que implican valorización urbana, ganancias de eficiencia, beneficios ambientales, principalmente, que pueden entenderse como potenciales operaciones privadas rentables que resultan igualmente beneficiosas iniciativas para la ciudad. Este trabajo trata precisamente con el esfuerzo de identificar los requisitos y la potencialidad de los suelos densificables, las condiciones que gobiernan la transformación y el éxito de tales operaciones y los beneficios que deberían obtenerse a partir de estas iniciativas.

\section{Procesos de crecimiento urbano}

Después de la migración campo-ciudad que marcó el fuerte crecimiento urbano de las ciudades latinoamericanas en las décadas de los años 50 a 70 del siglo pasado, se produjo más tarde un proceso de progresiva ralentización del crecimiento poblacional que cambió las tendencias del crecimiento urbano. Se redujeron paulatinamente el ritmo y la intensidad de ocupación de terrenos, la creación de campamentos por parte de migrantes internos y se generó una situación en la cual la tarea principal se concentraba en la promoción de sitios y servicios para la instalación de dichos migrantes.

La promoción de soluciones habitacionales, independientemente de su calidad, demandó suelos aptos para la localización de viviendas, representados por extensos paños que se encontraban naturalmente en la periferia, en particular, en zonas de borde no ocupadas hasta entonces y no urbanizadas.

En paralelo, el crecimiento del ingreso de sectores medios y medios bajos, en conjunto con el desarrollo de una industria inmobiliaria capacitada para la producción de viviendas en serie en paños periféricos urbanizables, se encargó también de ofrecer soluciones adicionales para esta parte de la población.

Todo ello se producía en el marco de dos fenómenos integrados para este fin y que han marcado de manera importante el crecimiento urbano: una ganancia económica que permitió emprender numerosos nuevos proyectos habitacionales y una evolución de las familias que les permitía pensar en la promoción habitacional a través de una nueva y mejor vivienda de reemplazo, localizada generalmente en conjuntos habitacionales de la periferia.

La ciudad se complementó con la localización de nuevos desarrollos de actividades administrativas, de servicios y comercio en nuevos subcentros ${ }^{2}$, que se acercaron a los nuevos sectores residenciales extendidos y con énfasis a aquellos vinculados a la población más acomodada de las ciudades.

De esta forma, las zonas centrales y pericentrales fueron perdiendo paulatinamente población y actividades, entrando en decadencia y muchas veces en abandono. Sin embargo, dichas zonas tienen potencial importante

\footnotetext{
${ }^{1}$ Ver, por ejemplo, la tesis de maestría de Daniel Moreno (2015), que muestra los procesos de obsolescencia y difícil renovación en áreas pericentrales de la ciudad de Santiago de Chile.

2 Ver, por ejemplo, los trabajos al respecto realizados por Adrián Guillermo Aguilar sobre México, en particular, Aguilar (2002).
} 
de localización de actividades, con suelo disponible y barato para renovación y habitualmente también, son parte importante de las redes de circulación de los sistemas tradicionales de transporte público, a menudo en ejes de mediana y alta capacidad.

\subsection{Extensión}

El incremento del ingreso ha presionado en las últimas dos a tres décadas la extensión urbana a partir de al menos dos expedientes de alta influencia: la demanda de mayor suelo urbano para residir (que se encuentra naturalmente en la periferia) y el incremento en la tasa de propiedad del automóvil, que permite con mayor facilidad cubrir mayores distancias en tiempos de viaje comparables ${ }^{3}$. Junto a esto, la evolución de las familias, en particular la reducción progresiva de su tamaño, ha constituido otro factor que empuja a la renovación y ampliación del parque de viviendas, presionando la periferia.

Paralelamente se produce un importante desarrollo de la industria inmobiliaria, que es capaz de implementar proyectos en residencias unifamiliares en gran escala, para lo cual recurre a suelos periféricos no ocupados anteriormente, donde es más barato y más fácil llevar a cabo estos proyectos. Si bien originalmente se orientaban a la demanda de población más rica (en particular, bajo la forma de las llamadas gated communities), poco a poco se van agregando proyectos menos ambiciosos para una gama socioeconómica más amplia de la población, que va logrando acceder al automóvil.

El incremento de precios del suelo en la periferia, debido a la mayor demanda ocasionada, hace que también se desarrolle edificación el altura, pero manteniendo zonas de baja densidad, con baja ocupación de suelo.

Acompañan a este desarrollo periférico la oferta de nueva edificación comercial, en particular bajo la forma de grandes centros comerciales con una sorprendente variedad de productos ofrecidos, como los malls, que incluyen el tradicional supermercado hasta atenciones de salud, oficios religiosos, cines y restaurantes; pero también otros centros de menor escala, como el formato de los strip centers, con menor ocupación de suelo y para atender demandas más focalizadas. Se consolida así un modo de vida suburbano que se reproduce fuertemente en la ciudad y que parece contar con todas las palancas y recursos para su subsistencia y reproducción, que incluye un uso intenso del automóvil, baja densidad, suelos altamente especializados y subcentralidades comerciales.

\subsection{Densificación}

A pesar del éxito de difusión del modelo de suburbanización, su estabilidad y eficiencia se ve cuestionada por dos factores principales. Por una parte, se verifica el crecimiento de los precios del suelo en la periferia (producto de la mayor demanda y menor disponibilidad del recurso) que limitan las posibilidades de fácil reproducción y continuidad; por otra parte, el incremento de los tiempos de viaje periferia - centro, debido al incremento de la congestión que resulta de un mayor número de automóviles circulando y de una imposibilidad de anteponer una oferta de infraestructura vial acorde con dicho crecimiento. Dentro de los casos extremos debe mencionarse la exagerada distancia entre nuevos desarrollos residenciales y los centros destinos de viaje, que ha llevado al abandono de tales urbanizaciones (por ejemplo, en Ciudad de México) o a la no demanda de sus viviendas.

En paralelo con esta situación, muchas ciudades comienzan a implementar desde principios de este siglo nuevos proyectos de transporte público de alta capacidad (en especial autobuses de tránsito rápido o BRT por sus siglas en inglés, y en mucho menor medida, metros y tranvías) que privilegian su recorrido por corredores que ingresan y/o se desenvuelven en áreas centrales y pericentrales. En concordancia con ello, y por las mismas razones expuestas, comienza a producirse una progresiva ocupación de las áreas centrales y de sus

3 Zahavi (1974) ya mostraba, en los años 70, que las personas mantenían constante su gasto en tiempos de viaje, de manera que una ganancia en la velocidad de estos los llevaba generalmente a trasladarse a vivir más lejos de sus destinos habituales de viaje. 
primeros anillos pericentrales a través de población joven, que se incorpora al mercado de trabajo y que en muchos casos accede a su vivienda propia más temprano.

Este nuevo residente del centro es joven, se sirve del transporte público o de la bicicleta (habitualmente no posee automóvil) para sus viajes, trabaja cerca de su domicilio y con su presencia y prácticas activa una oferta comercial y de servicios en el centro para la población residente o en tránsito. Esta situación consolida la perspectiva de recuperación de las áreas centrales al demostrar su atractividad y la factibilidad de muchas iniciativas que encuentran respuestas en la población ${ }^{4}$.

A partir de ello será necesario promover modalidades y prácticas que permitan que esta tendencia se consolide y se desarrolle más fuertemente.

\section{Densificación y renovación urbana}

Existen muchos aspectos que militan en favor de la densificación urbana a través de la renovación de zonas centrales, habitualmente deterioradas. Entre ellos, cabe destacar:

- Beneficios de localización que reducen los costos de accesibilidad de los residentes a distintas funciones urbanas, como el trabajo, el consumo, etc.

- Menores costos de urbanización, dada la existencia previa de las infraestructuras y los servicios, habitualmente con capacidad ociosa (sin embargo, debe advertirse que la densificación puede volver insuficientes los antiguos equipamientos e infraestructura por lo que deberá preverse en esos casos la implementación de nuevos proyectos)

- A pesar de un costo unitario mayor del suelo, su intenso uso en densidad permite que la alícuota por unidad de vivienda sea significativamente más bajo

- Importantes economías de aglomeración (en particular, de urbanización), que resultan de la concentración de diversos usos y de las dinámicas de mercado en estas zonas

- La alta probabilidad que en proyectos densificados sea posible comprar suelo a antiguos propietarios por un valor que justifique para ellos la venta, y que financie mejores condiciones residenciales (en localización y atributos de la vivienda).

Se propone analizar aquí, más allá de lo afirmado arriba, el fundamento de la densificación de zonas centrales de la ciudad. Asimismo, esto exige avanzar en la definición, discusión y alcance territorial de los impactos que pueden generar estos proyectos.

\section{Conformación de la oferta de suelo urbano}

La determinación de suelo urbano disponible exige analizar los factores que son relevantes para la densificación y renovación residencial. El proceso metodológico establece la aplicación de una serie de filtros que representan estos factores, los cuales pueden variar de acuerdo al contexto. Se debe señalar que la oferta que se pretende definir abarca el mercado de suelo e inmobiliario destinado a los usos residenciales.

Antes de entrar en cada uno de los filtros, se debe entender que el mercado de suelo, como muchos otros, no presenta condiciones próximas a la competencia perfecta, y depende de diversos factores además de la interacción entre oferta y demanda. Se parte de la base que la oferta total de suelo urbano se define a partir del límite urbano. Esto formaría el suelo edificable y que tiende a ser fijo en un periodo de tiempo más o menos prolongado, hasta que las autoridades decidan aumentar dicho límite. No obstante, este hecho no es sostenible a largo plazo y su expansión promueve prácticas que incrementan las externalidades negativas de las ciudades, como un mayor uso del automóvil y mayores costos de nueva infraestructura que cada vez tiene que

${ }^{4}$ Ver las definiciones de estos residentes del centro en Muñiz, y Daniel Calatayud (2006). 
llegar más lejos. En este punto, la justificación del incremento del límite urbano se hace para ampliar su oferta y con esto disminuir el precio del suelo debido a una mayor disponibilidad. No obstante, el criterio de densificación y renovación urbana hacen que no sea necesario incurrir a la medida expansionista de la ciudad.

Esto significa servirse de suelos que ya estaban construidos, aunque no en todo su potencial, para albergar a la mayor cantidad posible de población. La identificación de estos suelos, es justo lo que propone la presente metodología, que llevará posteriormente a definir criterios de densificación integral, dado que no puede tergiversarse este concepto y centrarlo solamente a que alcance el mayor número de habitantes en un determinado territorio de la ciudad.

\subsection{Normativa}

El primer filtro consiste en el análisis de la normativa existente, en el cual se debe verificar, a través de los instrumentos de planificación territorial, las zonas que están autorizadas para construir edificaciones con usos habitacionales. Esta base normativa puede variar de acuerdo al contexto de la ciudad o incluso del marco legal de cada país, por lo que su análisis es principalmente conceptual.

La normativa tiene estrecha relación con la zonificación, que consiste en establecer condiciones de usos, densidades, alturas, entre otros, en áreas delimitadas de la ciudad. En este sentido, la zonificación es relevante para impulsar o limitar el potencial desarrollo de estas áreas (Hook, Lotshaw y Weinstock, 2015). Sus definiciones específicas, pueden dirigir el tipo de edificaciones y usos a establecerse, promoviendo, por ejemplo, barrios residenciales, ejes comerciales o incluso nuevos potenciales sub-centros que promuevan mixtura de usos y se integren con proyectos urbanos de equipamiento e infraestructura de transporte.

Jaramillo (2009: 306) releva la planificación urbana del Estado debido a que ejerce una función reguladora, buscando "coherencia, equidad y eficiencia" en el mercado inmobiliario. Dicho mercado en áreas de la ciudad con poca o desactualizada definición de condiciones, pueden generar efectos indeseados como segregación socio-espacial, especulación, subutilización de terrenos centrales, usos no compatibles, congestión e incluso híper-densificación.

Entendiendo lo anterior, además de ser relevante para el control de externalidades urbanas, la normativa permite detectar aquellas áreas en las que se permite el uso residencial. A través de un análisis espacial, es posible definir una primera oferta de suelo potencial para su desarrollo con este filtro, que también puede funcionar si se descartan todas las zonas donde no es permitido o incluso donde no sería compatible con otros usos existentes, como las industrias pesadas y peligrosas para la salud.

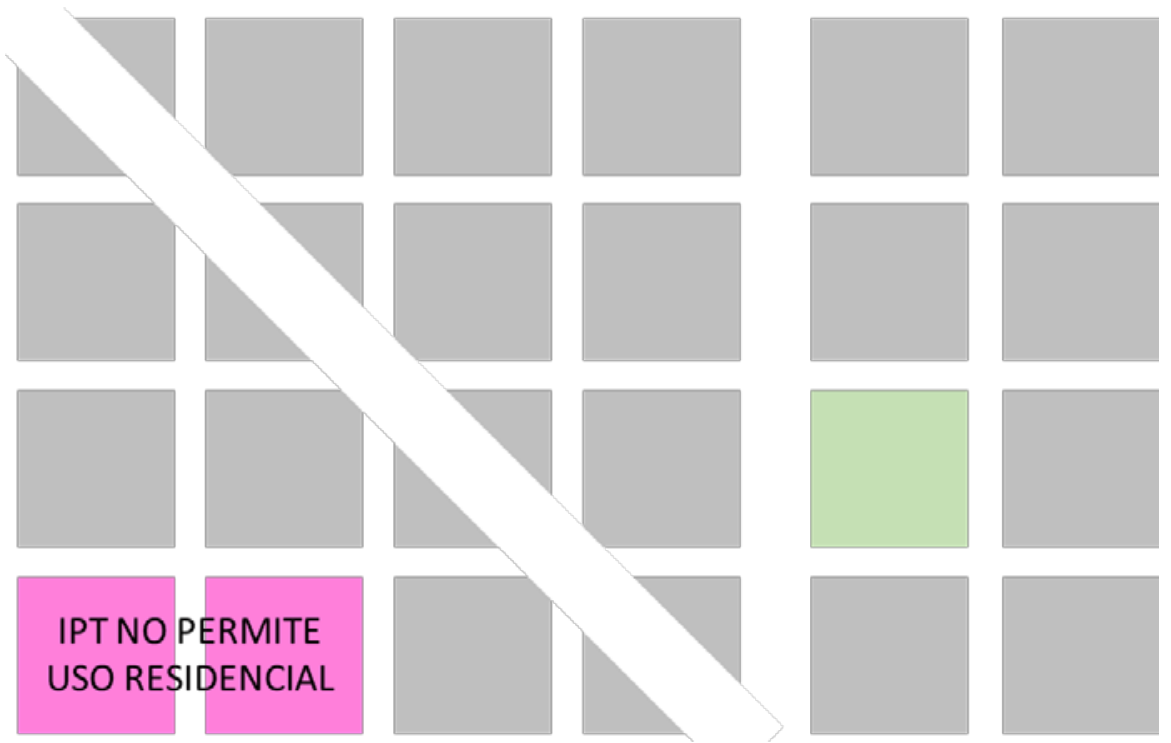

Fig. 01 Esquema conceptual de la aplicación del filtro por normativa. Fuente: Elaboración propia. 


\subsection{Usos de suelo}

En línea con lo anterior, la zonificación que permite los usos residenciales o mixtos establece áreas delimitadas que superan la escala predial o incluso la de la manzana. Por lo tanto, es necesario hacer un análisis más detallado, observando los usos de suelo protegidos y existentes por predio.

Dentro de la zonificación también se definen áreas o predios que, por su carácter patrimonial o cultural, están protegidos por norma. Inmuebles históricos, que representan parte de la identidad local o nacional, tienen resguardos amparados por leyes que hacen prácticamente imposible su modificación o cambio a otra tipología constructiva o incluso uso. De hecho, se han direccionado grandes esfuerzos en preservar estos inmuebles por parte de las autoridades, renunciando a posibles nuevos ingresos en relación a permisos constructivos e impuestos prediales.

Junto con estos usos inamovibles, existen otros que, a pesar de no estar protegidos, constituyen elementos relevantes para la calidad de vida urbana. Equipamientos educacionales o de salud entran en esta categoría, al igual que grandes superficies comerciales. Es un hecho que no todas las áreas delimitadas tienen necesariamente predios con usos habitacionales. Las tiendas, almacenes, restaurantes, cafés y oficinas en cierta medida, también pueden convivir con viviendas y generalmente esta situación es autorizada en la zonificación. Estos equipamientos y servicios de menor escala, pueden hacer parte de la reconversión al densificar con mixtura en los primeros niveles. Por otro lado, los equipamientos de mayor tamaño es poco probable que cedan ante esta situación, dado que, además de ser esenciales para la población (educación o salud), representan también un negocio rentable que perdura en el largo plazo (grandes superficies comerciales).

Por lo tanto, los predios que contienen tanto inmuebles protegidos por ser patrimoniales como aquellos que tienen grandes equipamientos dentro de las áreas que permiten usos residenciales, deben ser descartados de la oferta para densificación.

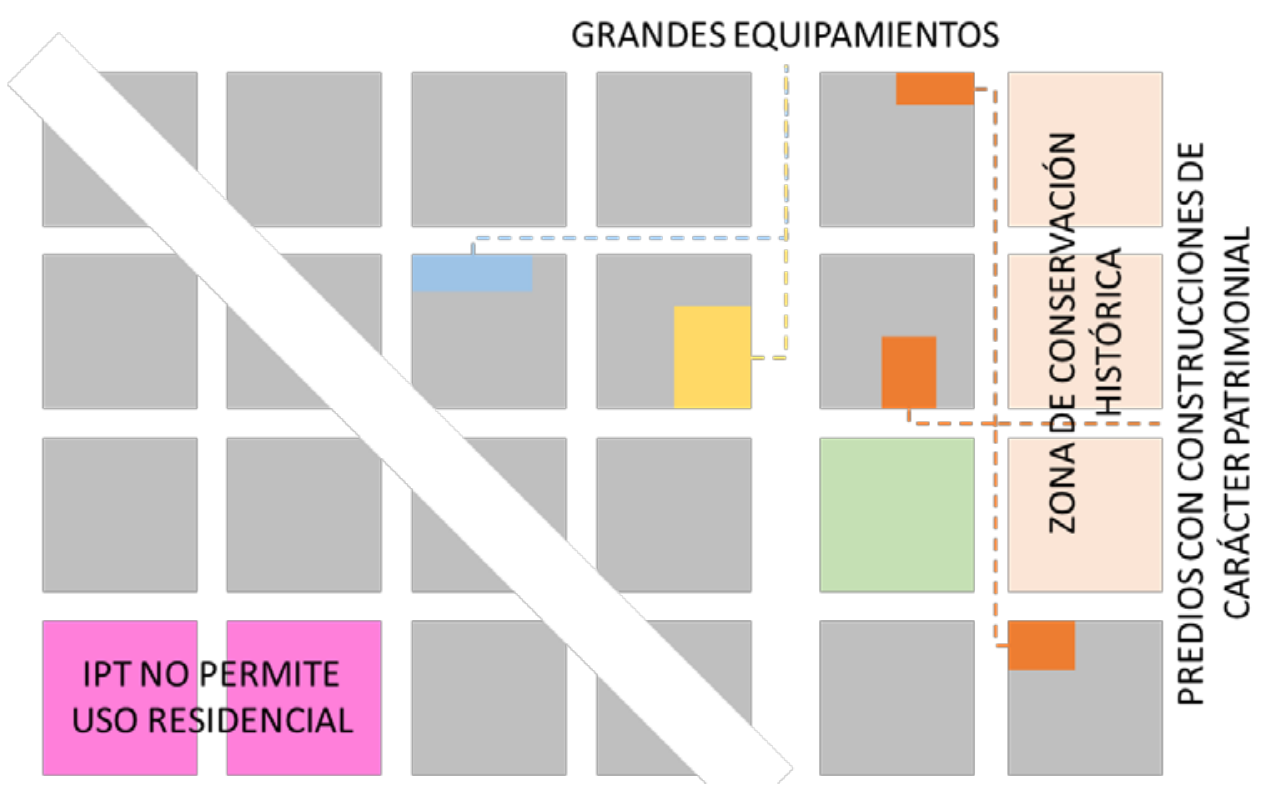

Fig. 02 Esquema conceptual de la aplicación del filtro de usos de suelo. Fuente: Elaboración propia.

\subsection{Altura}

Dentro de los costos del desarrollo inmobiliario se deben considerar aquellos que implican demoler inmuebles que pueden ser densificados. La determinación de estos costos puede variar de acuerdo al tipo de edificación 
existente, por lo que simplificar el análisis en este filtro puede ser de gran ayuda si se desea determinar la oferta de suelo para densificación.

La altura de las edificaciones puede ser una variable similar a los costos de demolición, dado que tienen una relación directamente proporcional. Por lo general, a mayor altura de la edificación existente será más superior el costo de su correspondiente demolición, elevando a su vez el costo total de un nuevo proyecto inmobiliario que se desee instalar en el predio ocupado. A partir de cierta altura en número de pisos, se deberá evaluar si se justifica o se descarta el predio para densificar.

Este factor, en todo caso, también depende de la disposición que tienen los desarrolladores inmobiliarios, al igual que del margen esperado de ganancia y su relación con los costos totales. No obstante, al descartar los predios con edificaciones más altas, además de la aplicación de los filtros anteriores, permite afinar más el análisis de oferta.

En general, debe esperarse que ceteris paribus, a mayor altura de un edificio, menos probable será su demolición y reemplazo.

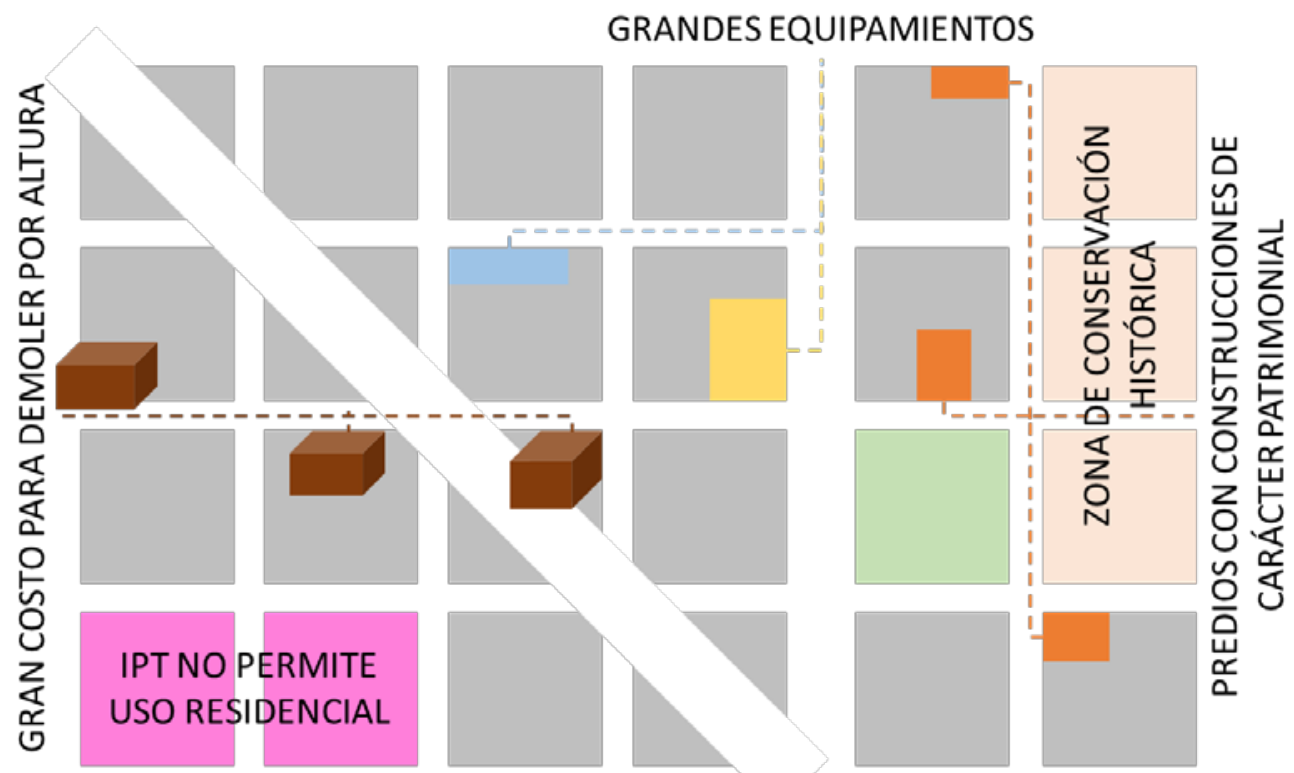

Fig. 03 Esquema conceptual de la aplicación del filtro de altura. Fuente: Elaboración propia.

\subsection{Antigüedad}

Otro factor relevante a considerar como filtro, se relaciona con la antigüedad de la edificación, considerando igualmente que los predios patrimoniales (usualmente los más antiguos) ya fueron descartados para la densificación. Las nuevas construcciones, a partir de cierto número de años, hacen poco probable su tendencia a la transformación. No obstante, al igual que el filtro precedente, este factor también depende del contexto y de la dinámica del mercado inmobiliario.

Al igual que en el caso anterior se debe esperar que ceteris paribus, a menor antigüedad de la edificación, menos probable será su reconstrucción. 


\section{SIIU Jank}

barcelona|santiago de chile junio 2019

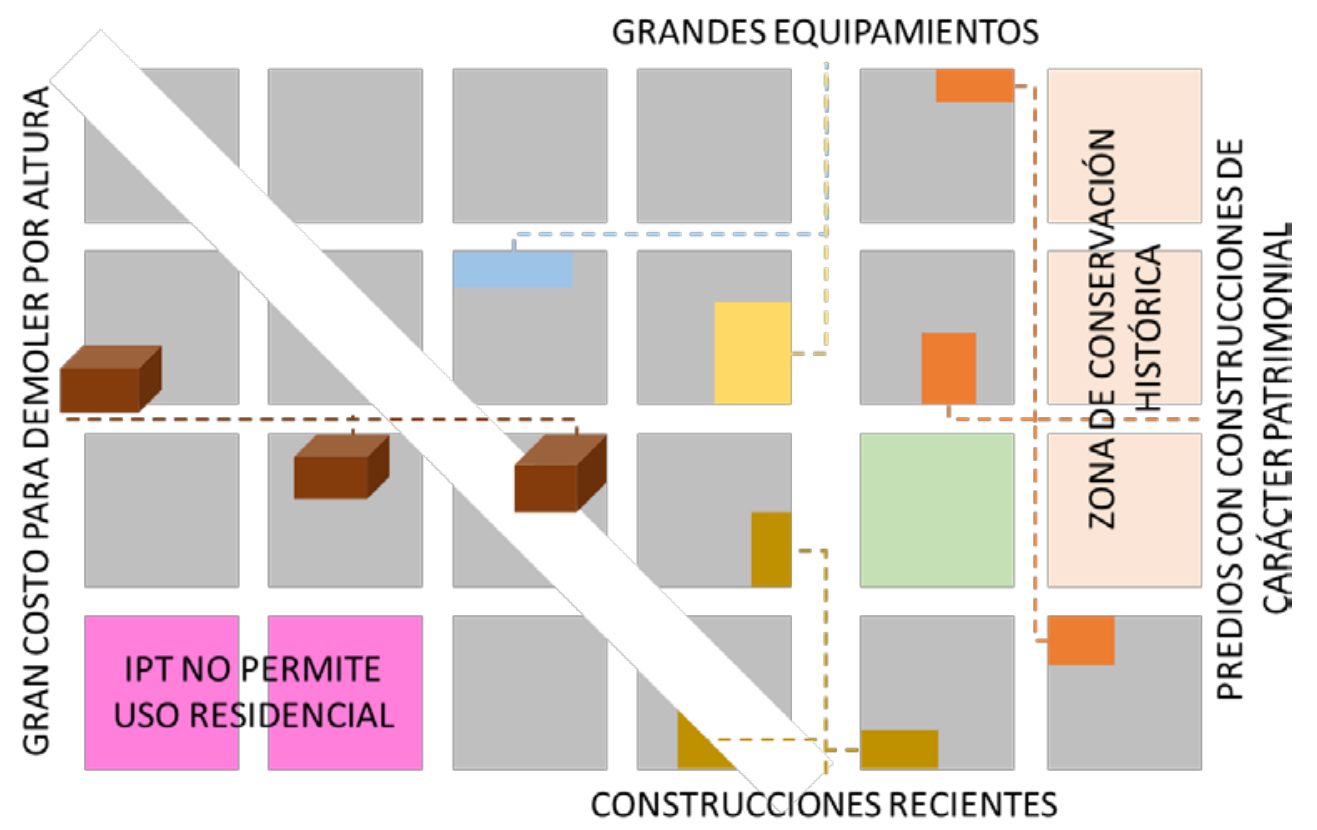

Fig. 04 Esquema conceptual de la aplicación del filtro de antigüedad. Fuente: Elaboración propia.

\subsection{Tamaño mínimo u óptimo predial}

El último filtro considera el tamaño mínimo u óptimo predial en el que se puede desarrollar un proyecto inmobiliario residencial denso. Generalmente este punto puede considerar tanto la normativa como marco regulatorio, aunque también es determinada por las tendencias del mercado inmobiliario.

La zonificación puede definir un tamaño predial mínimo en el que se permite el desarrollo de nuevos proyectos inmobiliarios, garantizando un área básica en la que se debe instalar una nueva construcción y determinando así ciertas tipologías edificatorias esperadas. No obstante, el mercado inmobiliario puede definir también el tamaño óptimo, basándose en la ubicación del proyecto y en el área densificable disponible (considerando los filtros anteriores). Generalmente, entre los predios disponibles próximos a los centros de las ciudades, se encuentran predios de gran tamaño (antiguas bodegas, almacenes, etc.) y otros de tamaño reducido (anteriores viviendas), por lo que los nuevos desarrollos tendrán opciones de renovar directamente o de promover un proceso lento y costoso de fusión de predios para alcanzar tamaños prediales recomendables para densificar. El riesgo aquí, y se conoce, es una fuerte densificación expresada en altas torres, con unidades de vivienda de pequeño tamaño, que a menudo tienen más costos sociales que beneficios. La compra de varios terrenos aledaños para fusionarlos y construir un proyecto inmobiliario de mayor capacidad representa costos mayores debido a los costos de transacción, pero significa también que se han optimizado otras variables como localización y potencial constructivo, que deriva a su vez en una mayor ganancia potencial y en mayores beneficios urbanos y ambientales.

La aplicación de este filtro, requiere de un análisis más detallado en comparación con los anteriores. Esto se debe a que la definición del óptimo puede variar no solo en razón de la normativa y tendencia, sino también en las múltiples posibilidades de fusión predial que siempre existen. 


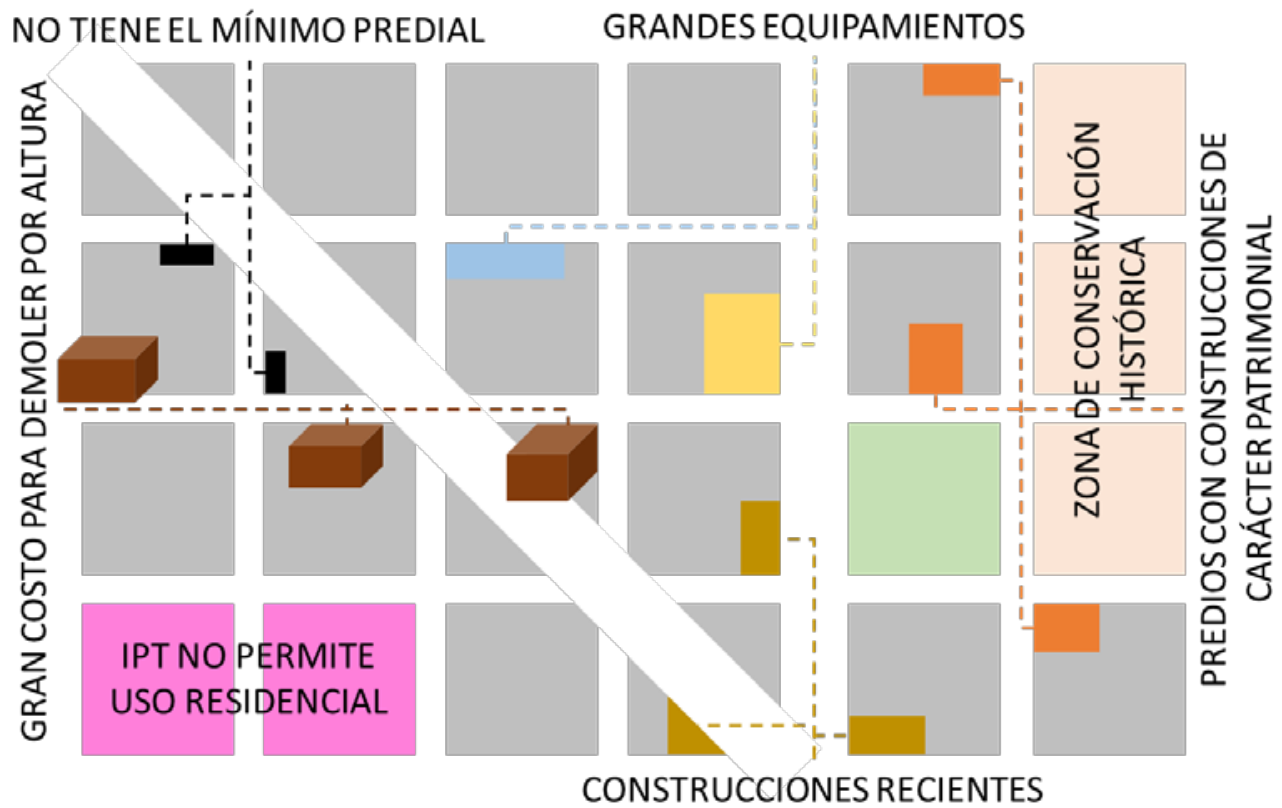

\section{EL ÁREA GRIS ES CORRESPONDE A LA OFERTA DE SUELO URBANO DISPONIBLE PARA RENOVACIÓN DENSIFICADA}

Fig. 05 Esquema conceptual de la aplicación del filtro de antigüedad. Fuente: Elaboración propia.

El siguiente esquema sintetiza el proceso metodológico de aplicación de filtros descrito en este apartado.

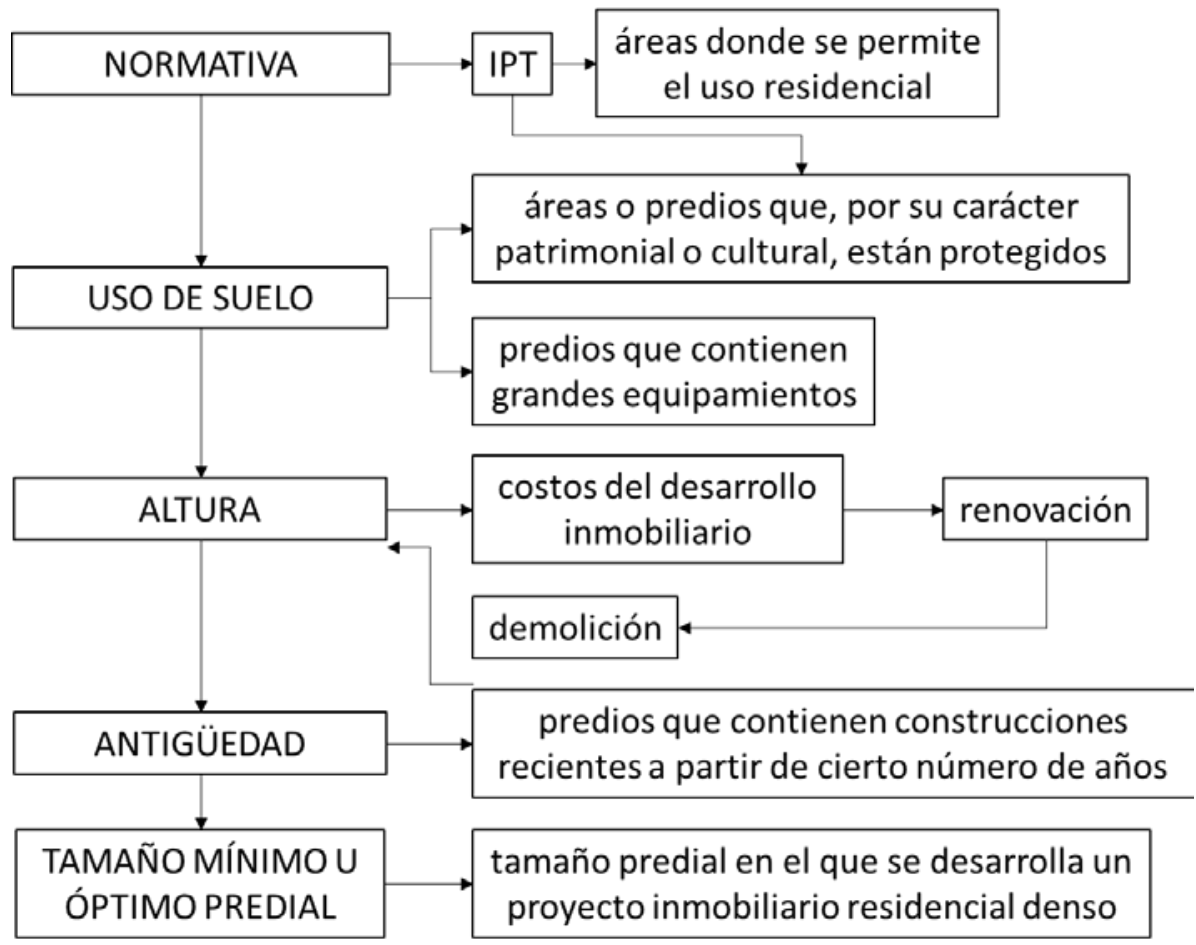

Fig. 06 Esquema metodológico del proceso de aplicación de filtros. Fuente: Elaboración propia. 


\section{Propuesta de criterios para densificación integral}

La densificación propuesta aquí se define como integral y no apunta a la densificación máxima permitida por el marco normativo, sino a una densificación que, con justa medida, aproveche los beneficios de las economías de aglomeración sin generar mayores externalidades negativas. Para esto, es necesario definir distintos criterios que constituyan la densificación integral.

El primero es la accesibilidad, tanto a equipamientos y servicios como a distintas zonas de la ciudad. La densidad y la ciudad compacta permiten disminuir distancias, aunque no así con los tiempos de viaje, que se pueden ver afectados por la congestión. Es por eso que los nuevos proyectos inmobiliarios deben estar cercanos a la red de transporte público, que les permita a las personas movilizarse más eficientemente con los menores costos sociales posibles. La aplicación de los filtros mencionados, en la medida de lo posible, debe considerarse alrededor de las zonas provistas de esta infraestructura, para maximizar los beneficios sociales tanto de vivienda como de accesibilidad. Además, Suzuki, Cervero e lushi (2013) aseguran que la integración entre transporte y los usos de suelo es un medio prometedor para contener la expansión urbana dependiente del uso del automóvil, pensando en un desarrollo urbano más sostenible.

La densidad integral debe considerar la convivencia entre usos residenciales y aquellos que les acercan más a las personas los bienes y servicios que necesitan. Introducir la mixtura de usos en nuevos proyectos inmobiliarios no solo impulsa la accesibilidad, sino también la compensación de la capacidad de carga de los grandes equipamientos. La densificación implica aumento de población en un territorio, población que debe satisfacer sus necesidades. El crecimiento poblacional tiende a ser lineal o incluso exponencial, mientras que el crecimiento de grandes equipamientos es escalonado, es decir, se instala cuando es necesario y hasta agotar su capacidad, se construye otro. La compensación de usos mixtos disminuye, en cierta medida la congestión de los grandes equipamientos y da cabida a nuevos emprendimientos y empleos. Asimismo, en planes de densificación que abarcan grandes superficies urbanas, debe cederse un porcentaje de predios destinados a equipamientos básicos y no solamente la primera planta delas nuevas edificaciones.

Existe una deuda histórica en relación con la vivienda social en la evolución, crecimiento y desarrollo de las ciudades. La localización en la periferia de este tipo de vivienda por suelos más baratos, al igual que el afán de las autoridades por resolver el déficit cuantitativo, ha perjudicado la calidad de vida urbana de personas de escasos recursos. La densificación integral representa una oportunidad de reivindicación, dado que no solo debe apostar por la mixtura de usos, sino también por la integración social. Incluir un porcentaje de vivienda social en las unidades residenciales dentro de los nuevos proyectos inmobiliarios en densificación, permite a personas de escasos recursos acceder más fácilmente a equipamientos, servicios y a los principales mercados laborales de la ciudad.

La institucionalidad pública y el control del desarrollo urbano deben manifestarse a la hora de verificar el cumplimiento de los nuevos proyectos residenciales. En este mercado, por lo general los agentes inmobiliarios tienen un fuerte deseo de incrementar altura o densidad, e incluso en algunos países existen instrumentos que otorgan bonos de densidad a cambio de obras públicas o aportes financieros (Hook, Lotshaw y Weinstock, 2015). La regulación sobre la densidad debe ser exhaustiva y restrictiva, estableciendo límites máximos acorde al entorno del barrio y al modelo de densidad de la ciudad deseado, a través de índices de constructibilidad, altura, ocupación de suelo e incluso unidades habitacionales (Jaramillo, 2009).

\section{Conclusiones}

Las ciudades están en constante crecimiento. Sea por extensión o densidad, la población necesita un lugar donde vivir y satisfacer sus necesidades y está en manos de las autoridades y de los agentes inmobiliarios definir el cómo. La densidad integral representa una oportunidad para dar cabida a nuevos habitantes sin reproducir las externalidades negativas de la planificación de décadas anteriores. 
Conocer la oferta de suelo para la renovación densificada, permite a los planificadores tener mayor control sobre el mercado inmobiliario. Además, con los criterios expuestos, permite orientar el desarrollo urbano en conjunto con la construcción de infraestructuras y equipamientos, considerando mantener siempre una capacidad de carga que garantice una adecuada calidad de vida urbana.

La densificación no significa aprovechar el máximo establecido por la norma para introducir población en un territorio. Significa validar la existencia de las ciudades y los beneficios que trae la proximidad entre personas y actividades. Mayor altura no necesariamente es equivalente a mayor cantidad de habitantes y de ganancias para los agentes inmobiliarios. Una adecuada distribución entre constructibilidad y ocupación de suelo permiten obtener la misma cantidad de personas y ganancias con menos pisos en las edificaciones. Además, incluir otros usos e incluso ceder parte del predio a espacio público para la movilidad peatonal, genera beneficios sociales adicionales, los cuales pueden nacer desde de un proyecto que es de carácter privado.

\section{BIBLIOGRAFÍA}

AGUILAR. A. (2002). Las mega-ciudades y las periferias expandidas. Ampliando el concepto en Ciudad de México. Revista Eure (Santiago de Chile), Vol. XXVIII, No 85 121-149.

GARCÍA ROMERO, A. y FERNÁNDEZ ALADO, C. (1996). El sistema educativo en la nueva reforma. Revista de Educación (Madrid), 309, 498-789.

HOOK, W., LOTSHAW, S. y WEINSTOCK, A. (2015). Un mayor desarrollo gracias a cada dólar invertido en transporte público: Análisis de 21 Corredores de transporte en Estados Unidos de América. The Institute for Transportation and Development Policy.

JARAMILLO, S. (2009). Hacia una teoría de la renta del suelo urbano. Bogotá: Universidad de los Andes, Facultad de Economía, CEDE, Ediciones Uniandes.

MORENO, D. (2015). El estado actual del pericentro urbano de Santiago. La oportunidad configurada por el deterioro (tesis de magíster). Instituto de Estudios Urbanos y Territoriales. Pontifica Universidad Católica de Chile. Santiago de Chile.

MUÑIZ, I., GARCIA, M. y CALATAYUD (2006). SPRAWL. Definición, causas y efectos. Working Papers wpdea0603. Departament d'Economia Aplicada. Universitat Autonoma de Barcelona.

SUZUKI, H., CERVERO, R. y IUSHI, K. (2013). Transformando las ciudades con el transporte público. Integración del transporte público y el uso del suelo para un desarrollo urbano sostenible. Bogotá: Universidad de los Andes, Facultad de Ingeniería, Ediciones Uniandes.

ZAHAVI, Y. (1974). Travel Time Budgets and Mobility in Urban Areas. Report US Department of Transportation. Washington DC. 